\title{
Aggregation properties of levofloxacin in water and ethanol and its interaction with sodium dodecyl sulphate: A thermodynamic study
}

\author{
MUHAMMAD SHAKEEL ${ }^{\mathrm{a}, *}$, KHALID MEHMOOD ${ }^{\mathrm{a}}$ and MOHAMMAD SIDDIQ ${ }^{\mathrm{b}}$

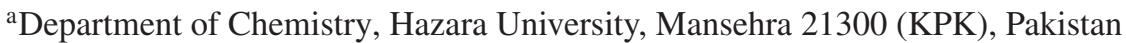 \\ ${ }^{\mathrm{b}}$ Department of Chemistry, Quaid-e-Azam University, Islamabad 45320, Pakistan \\ e-mail: m_s313141@yahoo.com
}

MS received 7 April 2015; revised 15 September 2015; accepted 20 September 2015

\begin{abstract}
This manuscript reports the determination of critical micelle concentration (CMC) of levofloxacin (LF) in two solvents, water and ethanol, by using surface tension, refractive index and absorbance measurements. The data thus obtained were used to calculate different thermodynamic parameters for micellization process like free energy of micellization, free energy of adsorption, entropy and enthalpy of micellization. The interaction of this drug with anionic surfactant (SDS) was also studied using UV/Visible spectroscopy and conductometry. With rise in temperature, CMC of the drug was found to decrease in ethanol and increase in aqueous solution indicating dominance of lipophobic desolvation over lipophilic desolvation in ethanol and reverse, in case of aqueous solution. A strong drug/surfactant interaction was found to exist. The data obtained from drug/surfactant interaction were also used to find different interaction parameters like partition constant, free energy of partition, binding constant and free energy of binding which are very useful to understand the phenomenon of solubilization.
\end{abstract}

Keywords. Levofloxacin; solubilization; micellization; UV/Visible spectroscopy; partition coefficient.

\section{Introduction}

The physico-chemical properties of drugs in solution play a very important role in drug design and development which depend on different parameters. ${ }^{1}$ Just like other surfactants or amphiphiles, most of the drugs form micelles in solution which are aggregates of drug molecules. If such a drug is administrated in body in large amount then it may also form aggregates which may get accumulated at different parts of body due to their large size. ${ }^{2}$ These micelles decrease the transport rate and cause different types of diseases. ${ }^{2}$ The concentration of drug at which it starts to form micelles, critical micelle concentration (CMC), depends on different factors like temperature, pressure and presence and concentration of added substance. These micelles have the ability to increase the solubility of partially soluble and insoluble substances because in micelles there is anisotropic distribution of water. This results in the solubilization of other substances either in micellar core or at intermediate position between micellar surface and core. $^{3}$ These micelles are also similar to biomembranes and can be used as alternative to biomembranes to study

*For correspondence the drug-membrane interaction in vitro because most drugs act by interaction with biomembranes. ${ }^{4-6}$

Our present work is related to the determination of CMC of levofloxacin (LF) in water and ethanol by using surface tension, refractive index and absorbance measurements at four temperatures. The interaction of this drug with anionic surfactant sodium dodecyl sulphate (SDS) was also studied using UV/Visible spectroscopy and conductance measurements. It has been observed that workers mostly select electrolytic drugs for such studies but we have selected non-electrolytic drug (LF) so that micellar behavior of such a drug can be studied. The interaction of the same drug with sodium dodecyl sulphate using conductometric, FTIR and ${ }^{1} \mathrm{H}-\mathrm{NMR}$ analysis has recently been studied by Bhardwaj et al. ${ }^{7}$ However, determination of CMC of LF in aqueous and ethanolic solutions has not been reported. ${ }^{7}$

Levofloxacin belongs to floroquinole class of drugs and is a well known broad spectrum antibiotic. It is mostly used for the treatment of respiratory, abdominal, gastrointestinal and urinary tract infections as it is effective against both gram positive and gram negative bacteria. ${ }^{8}$ It is found to have excellent tissue penetration and is available in both oral and intravenous formulation which makes it a very popular medicine. Solubility of levofloxacin is $\mathrm{pH}$ dependent. At pH 5.8 the solubility increases and reaches its maximum at about pH 6.7. 
In this range it is freely soluble. Above $\mathrm{pH} 6.7$ solubility of the drug decreases and becomes minimum at a $\mathrm{pH}$ of $6.9 .^{8}$

\section{Experimental}

\subsection{Solution Preparation}

LF ( $\geq 99 \%$ purity) was purchased from Fluka, absolute ethanol from Merck and sodium dodecyl sulphate ( $\geq 98.5 \%$ purity) from BDH. The structure of LF is shown in scheme 1 . The solutions of drug having different concentrations $\left(\mathrm{mol} \mathrm{kg}^{-1}\right)$ were prepared in double distilled and deionized water having conductivity less than $2 \mu \mathrm{S} \mathrm{cm}^{-1}$ and dry absolute ethanol using a balance (Rice Lake TA-120) with precision of $\pm 0.0001 \mathrm{~g}$ for CMC measurements. However, for studying drugsurfactant interaction standard aqueous solution of drug was prepared and diluted to such a concentration that maximum absorbance remained below unity so that Beer-Lambert law remained applicable. This solution was used as solvent to prepare solutions of surfactant of different concentrations in pre- to post-micellar range.

\subsection{Apparatus and Methods}

Surface tension measurements of drug solutions were taken with the help of Torsion Balance (White Elect. Inst. Co. Ltd.) provided with platinum ring (circumference $=4.0 \mathrm{~cm}$ ). Constant temperature was maintained in a water circulating bath (Irmeco I- $1800 \mathrm{GmbH}$, Germany) having temperature control accuracy of $\pm 0.5^{\circ} \mathrm{C}$. The torsion balance was calibrated with water. UVVisible spectrophotometer (Lambda 20, Perkin Elmer) was used for absorption spectra. Spectrophotometer is equipped with a water jacketed cell compartment to get constant temperature with an accuracy of $\pm 0.5^{\circ} \mathrm{C}$. Quartz cuvettes of path length $1.0 \mathrm{~cm}$ were used. Refractive index measurements of drug solutions were taken at room temperature using refractometer (ABBE 2WAJ,PCE Instruments) having accuracy of \pm 0.0002 .<smiles>C[C@H]1COc2c(N3CCN(C)CC3)c(F)cc3c(=O)c(C(=O)O)cn1c23</smiles>

Scheme 1. Structure of Levofloxacin.

\section{Results and Discussion}

\subsection{Critical Micelle Concentration}

The surface tension of different aqueous solutions of LF was determined and plotted versus molal concentration of drug as shown in figure 1. CMC can be determined from the point of intersection of lines in the plot in pre- and post-micellar region which was found to be $0.058 \mathrm{~mol} \mathrm{~kg}^{-1}$ in aqueous medium. ${ }^{2}$ This value of $\mathrm{CMC}$ is close to that determined by refractive index (figure 2) and absorbance (figure 3) measurements $\left(0.060 \mathrm{~mol} \mathrm{~kg}^{-1}\right)$ at the same temperature. The surface tension of LF in ethanol was found to change so minutely with concentration that it could not be used to find CMC of drug in ethanol. So absorbance and refractive index measurements were used to find $\mathrm{CMC}$ in ethanol. In ethanol the value of CMC for LF was found to be $0.0204 \mathrm{~mol} \mathrm{~kg}^{-1}$ as determined by absorbance measurements (figure 4 ) which is close to that determined by refractive index method (figure 5) i.e., $0.020 \mathrm{~mol} \mathrm{~kg}^{-1}$ at $298 \mathrm{~K}$.

The surface excess concentration is the concentration of LF adsorbed at air-solution interface in excess to that present in bulk of solution and for non-ionic surfactants it can be calculated by using Gibbs adsorption equation as given below. ${ }^{9}$

$$
\Gamma_{2}=-\frac{1}{R T}\left(\frac{d \gamma}{d \ln m}\right)_{T}
$$

Here, $\mathrm{R}$ is ideal gas constant, $\mathrm{T}$ is temperature, $\gamma$ is surface tension of solutions and $\mathrm{m}$ is concentration in mole $\mathrm{kg}^{-1}$. The values of surface excess concentration for LF indicate higher concentration of drug at solution-air interface as compared to that in bulk aqueous medium.

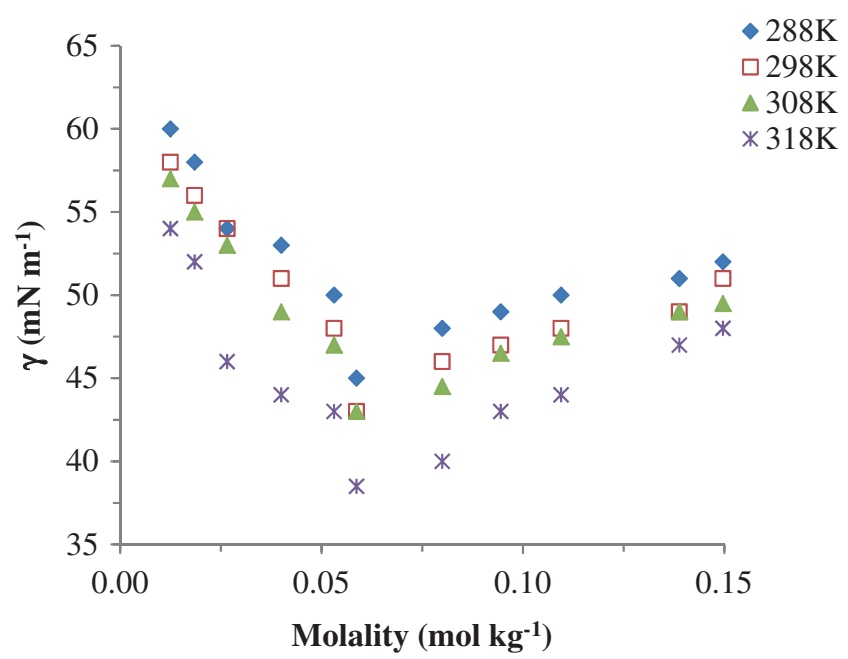

Figure 1. Surface tension versus concentration plots for LF in water at different temperatures. 


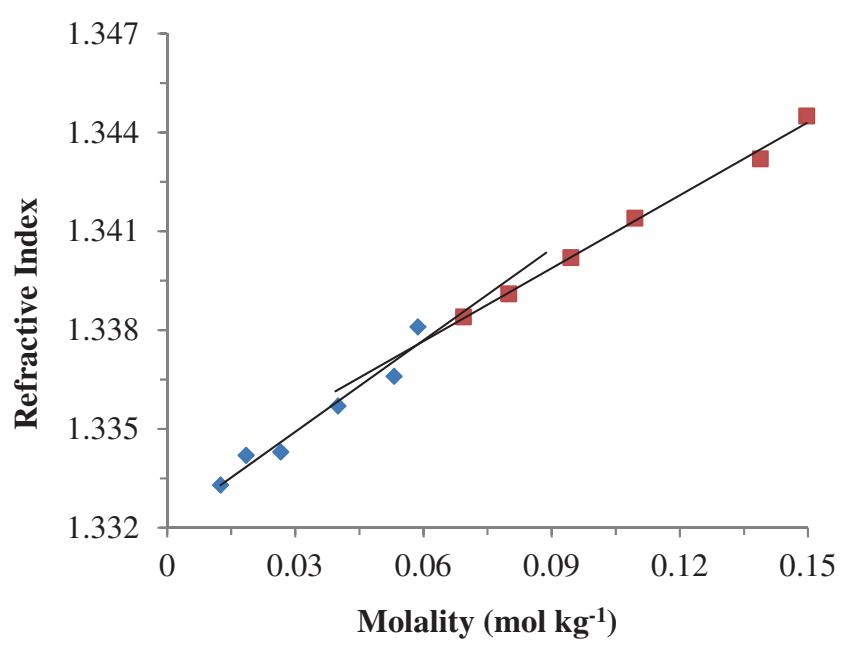

Figure 2. Refractive index versus concentration plot for $\mathrm{LF}$ in water at $298 \mathrm{~K}$.

The minimum area per molecule at solution-air interface is given by relation $A=1 / \mathrm{N}_{\mathrm{A}} \Gamma_{2}$. In this relation, $\mathrm{N}_{\mathrm{A}}$ is Avogadro's number and $\Gamma_{2}$ is surface excess concentration of LF. It represents the extent of packing and orientation of adsorbed drug molecules.

Standard free energy change of micellization $\left(\Delta \mathrm{G}_{\mathrm{m}}^{\circ}\right)$ can be calculated by equation (2) and standard free energy change of adsorption $\left(\Delta \mathrm{G}_{\mathrm{ads}}^{\circ}\right)$ by equation (3) using $\mathrm{X}_{\mathrm{CMC}}\left(\mathrm{CMC}\right.$ in mole fraction). ${ }^{9}$

$$
\begin{gathered}
\Delta G_{m}^{\circ}=R T \ln X_{C M C} \\
\Delta G_{a d s}^{\circ}=\Delta G_{m}^{\circ}-\frac{\pi_{C M C}}{\Gamma_{2}}
\end{gathered}
$$

Where $\pi_{C M C}$ is the surface pressure at CMC and is calculated by using surface tension of solvent $\left(\gamma_{0}\right)$ and

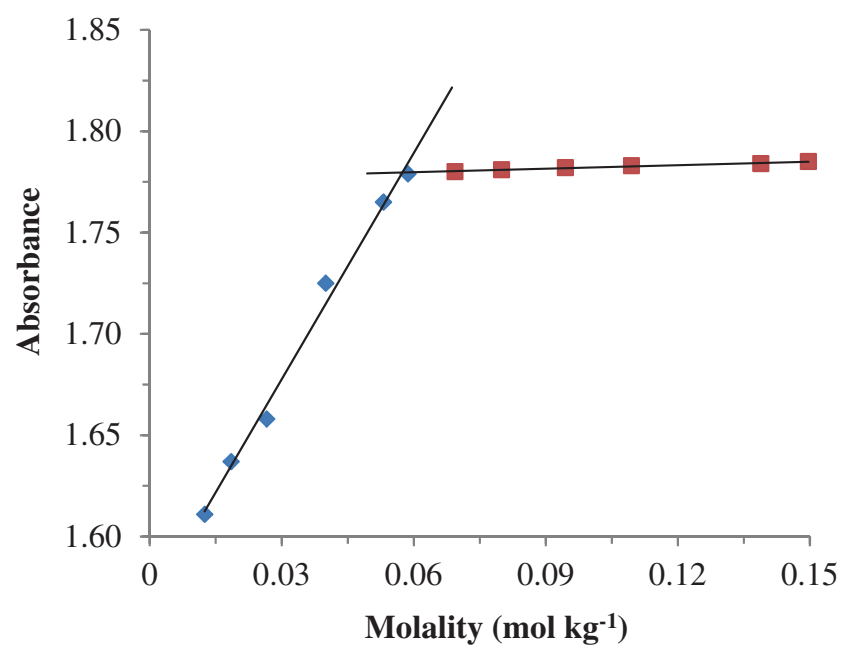

Figure 3. Absorbance versus concentration plot for LF in water at $298 \mathrm{~K}$.

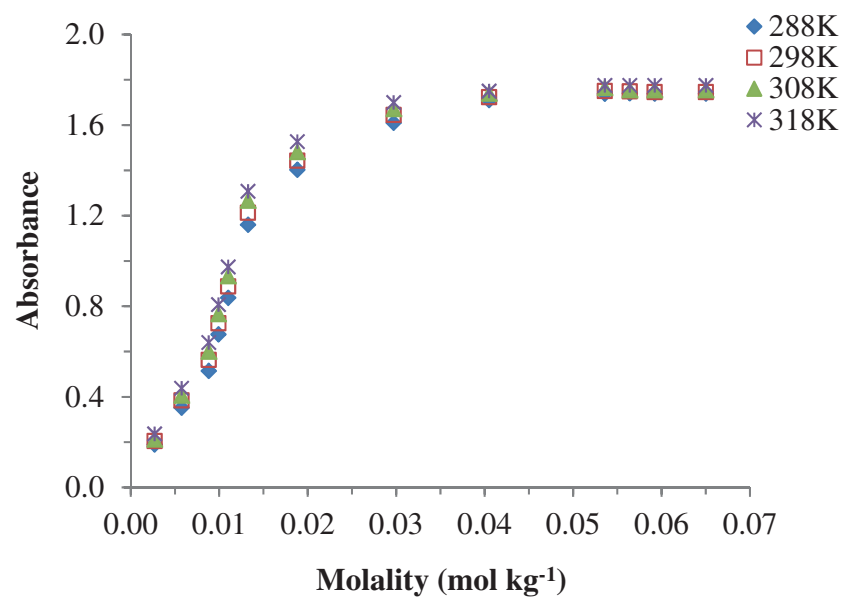

Figure 4. Absorbance versus concentration plot for LF in ethanol at different temperatures.

surface tension of drug at $\mathrm{CMC}\left(\gamma_{c m c}\right)$ by the following relation. ${ }^{9}$

$$
\pi_{\mathrm{cmc}}=\gamma_{\circ}-\gamma_{c m c}
$$

Tables 1 and 2 show that the CMC of drug increases with temperature rise in water and decreases in ethanol. The reason for this change in CMC is that there are two opposing processes which affect CMC with temperature change. Firstly, the increase in temperature decreases hydrophobic hydration which favors micellization and tends to decrease CMC. Secondly, the increase in temperature decreases hydrophilic hydration which disfavors micellization and increases CMC because this decrease in dehydration increases the repulsive interaction between ionic head groups making micellization unfavorable. ${ }^{9}$ Relative magnitude of these opposing processes decides the change in CMC. In

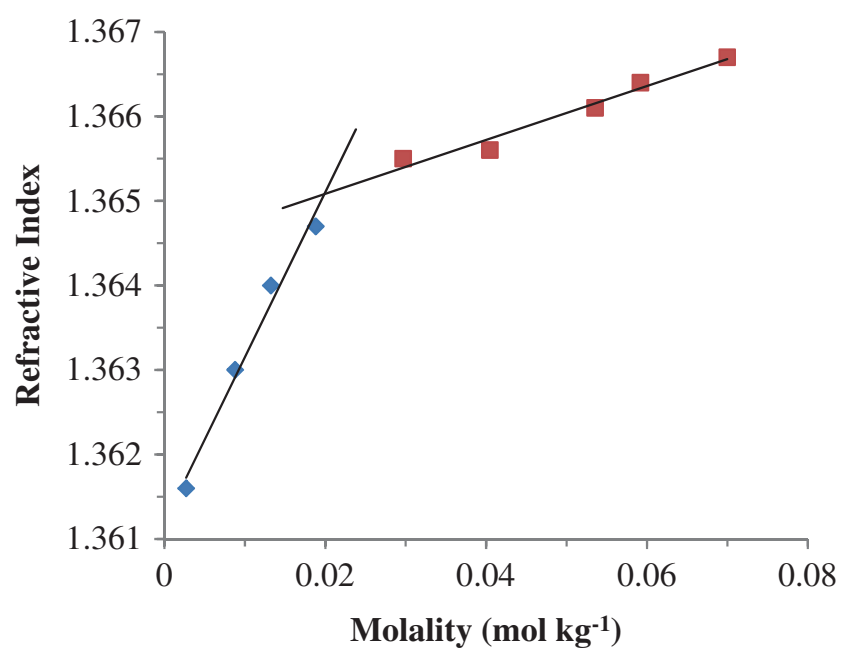

Figure 5. Refractive Index versus concentration plot for LF in ethanol at $298 \mathrm{~K}$. 
Table 1. Critical micelle concentration, $\mathrm{CMC}$, enthalpy of micellization, $\Delta \mathrm{H}_{\mathrm{m}}^{\circ}$, free energy of micellization, $\Delta \mathrm{G}_{\mathrm{m}}^{\circ}$, and entropy of micellization, $\Delta \mathrm{S}_{\mathrm{m}}^{\circ}$, for aqueous solution of $\mathrm{LF}$ at different temperatures.

\begin{tabular}{cccccc}
\hline $\mathrm{T}(\mathrm{K})$ & $\mathrm{CMC}\left(\mathrm{mol} \mathrm{kg}{ }^{-1}\right)$ & $\mathrm{CMC} \times 10^{4}(\mathrm{X})$ & $\Delta \mathrm{G}_{\mathrm{m}}^{\circ}\left(\mathrm{kJ} \mathrm{mol}^{-1}\right)$ & $\Delta \mathrm{H}_{\mathrm{m}}^{\circ}\left(\mathrm{kJ} \mathrm{mol}^{-1}\right)$ & $\Delta \mathrm{S}_{\mathrm{m}}^{\circ}\left(\mathrm{J} \mathrm{K}^{-1} \mathrm{~mol}^{-1}\right)$ \\
\hline 288.0 & $0.0580 \pm 0.001$ & $10.44 \pm 0.19$ & $-16.44 \pm 0.05$ & $-2.89 \pm 0.33$ & $47.02 \pm 1.02$ \\
298.0 & $0.0595 \pm 0.001$ & $10.69 \pm 0.18$ & $-16.99 \pm 0.04$ & $-3.10 \pm 0.36$ & $46.47 \pm 1.12$ \\
308.0 & $0.0600 \pm 0.002$ & $10.80 \pm 0.42$ & $-17.49 \pm 0.09$ & $-3.31 \pm 0.38$ & $46.04 \pm 1.57$ \\
318.0 & $0.0620 \pm 0.001$ & $11.16 \pm 0.15$ & $-17.97 \pm 0.04$ & $-3.53 \pm 0.40$ & $45.47 \pm 1.23$ \\
\hline
\end{tabular}

Table 2. CMC values of LF in ethanol at different temperatures.

\begin{tabular}{lll}
\hline $\mathrm{T}(\mathrm{K})$ & $\mathrm{CMC}(\mathrm{mol} \mathrm{kg}$ & $\mathrm{CMC} \times 10^{4}(\mathrm{X})$ \\
\hline 288.0 & $0.0208 \pm 0.0002$ & $9.57 \pm 0.09$ \\
298.0 & $0.0204 \pm 0.0001$ & $9.38 \pm 0.07$ \\
308.0 & $0.0202 \pm 0.0002$ & $9.29 \pm 0.10$ \\
318.0 & $0.0200 \pm 0.0001$ & $9.20 \pm 0.01$ \\
\hline
\end{tabular}

aqueous solution, the decrease in hydrophilic hydration is dominant over hydrophobic hydration with temperature rise while reverse is observed in ethanol solution. ${ }^{10}$

It is apparent from table 3 that values of $\Delta \mathrm{G}_{\mathrm{m}}^{\circ}$ are negative showing that the process of micellization of LF i.e., the conversion of molecules of drug from bulk aqueous solution to the micellar phase is spontaneous. Negative $\Delta \mathrm{G}_{\mathrm{ads}}^{\circ}$ shows that the process of adsorption of drug molecules at solution-air interface is also spontaneous. ${ }^{10} \Delta \mathrm{G}_{\mathrm{ads}}^{\circ}$ is more negative than $\Delta \mathrm{G}_{\mathrm{m}}^{\circ}$ representing that the adsorption process is more spontaneous as compared to micellization and completes before micellization. Values of $\Delta \mathrm{G}_{\mathrm{ads}}^{\circ}$ and $\Delta \mathrm{G}_{\mathrm{m}}^{\circ}$ become more negative with temperature rise showing that these processes become more spontaneous at elevated temperature. ${ }^{11} \Delta \mathrm{H}_{\mathrm{m}}^{\circ}$ is negative showing that the process of micellization is exothermic and becomes more exothermic at higher temperature. ${ }^{11}$

$\Delta \mathrm{S}_{\mathrm{m}}^{\circ}$ is positive at all temperatures showing that transfer of hydrophobic chains of drug molecules from the aqueous solution to micellar phase results in increase in entropy. It is found that the hydrophobic chains of drug molecules cause increase in the structure of water by creating stronger hydrogen bonding between water molecules around the hydrophobic chains of drug molecules. ${ }^{11}$ This type of interaction is called hydrophobic hydration. Due to this hydrophobic hydration, tightening of water structure around the hydrophobic chains occurs which also causes the torsional vibration of chains to become restricted. ${ }^{11}$ As a result, decrease in randomness or entropy of system occurs. When these chains shift into micellar phase, destruction of water structure takes place due to decrease in hydrophobic hydration which increases the entropy of system. ${ }^{12}$ Decrease in entropy of micellization with temperature rise means that hydration of hydrophobic parts of drug molecules decreases as temperature is raised. ${ }^{13}$

\subsection{Interaction of LF with Surfactants}

3.2a Simple Absorption Spectra: Simple absorbance spectra were obtained for solutions of SDS of different concentrations in pre and post-micellar region containing constant concentration of LF in sample side and double distilled deionized water in reference side of spectrophotometer. The concentration of LF was kept constant at $1.3175 \times 10^{-5} \mathrm{~mol} \mathrm{dm}^{-3}$. It is observed that the absorbance first increases rapidly and then slowly. This increase in absorbance shows a strong interaction of drug with surfactant which is due to incorporation of drug molecules into the micellar phase of SDS called solubilization which occurs due to adsorption of solubilizate (drug molecule) on the surface of micelles, orientation near the surface (short penetration) or entrapping in the hydrocarbon core (deep penetration). ${ }^{14}$

The CMC of pure SDS is $0.0082 \mathrm{~mol} \mathrm{dm}^{-3}$, which decreases in the presence of LF to $0.0076 \mathrm{~mol} \mathrm{dm}^{-3}$

Table 3. Free energy of adsorption, $\Delta \mathrm{G}_{\mathrm{ads}}^{\circ}$, surface excess concentration, $\Gamma_{2}$, and area per molecule, A, for LF in water at different temperature.

\begin{tabular}{cccc}
\hline $\mathrm{T}(\mathrm{K})$ & $\Gamma_{2} \times 10^{6}\left(\mathrm{~mol} \mathrm{~m}^{-2}\right)$ & $\mathrm{A}\left(\mathrm{nm}^{2}\right)$ & $\Delta \mathrm{G}_{\mathrm{ads}}^{\circ}\left(\mathrm{kJ} \mathrm{mol}^{-1}\right)$ \\
\hline 288.0 & $2.83 \pm 0.01$ & $0.587 \pm 0.003$ & $-25.80 \pm 0.27$ \\
298.0 & $2.74 \pm 0.10$ & $0.606 \pm 0.023$ & $-26.84 \pm 0.56$ \\
308.0 & $2.64 \pm 0.46$ & $0.629 \pm 0.094$ & $-28.29 \pm 0.87$ \\
318.0 & $2.62 \pm 0.14$ & $0.634 \pm 0.024$ & $-29.79 \pm 0.59$ \\
\hline
\end{tabular}




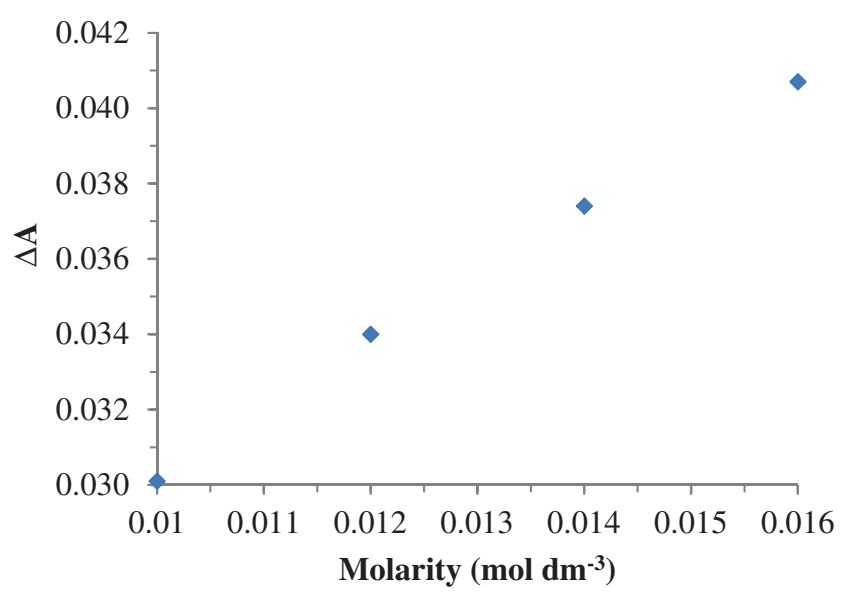

Figure 6. Variation of differential absorbance with change in concentration for LF/SDS system.

(determined by simple absorbance measurements) due to solubilization of molecules of LF on SDS between the anionic head groups of SDS micelles. This type of solubilization reduces repulsion between ionic head groups and favours micellization of SDS thus decreasing CMC. Another reason for decrease in CMC is structure making effect of LF which causes ordering of water molecules and increases entropy on micellization thus making micellization entropically more favorable and decreasing CMC. ${ }^{15}$

3.2b Differential spectroscopy: Differential (difference) spectroscopy is very important for understanding partition behavior of drug between aqueous and micellar phase. Differential spectra are obtained by taking a solution of LF without SDS in reference side and solutions of SDS containing identical concentration of drug in the sample side. As apparent from figure 6 and table 4 , an increase in value of differential absorption with concentration rise of SDS is observed indicating stronger LF/SDS interaction. ${ }^{16}$

3.2c Drug/Micelle Partition Coefficient: Partition coefficient is ratio of mole fraction of drug present in micelles to that present in bulk aqueous solution and

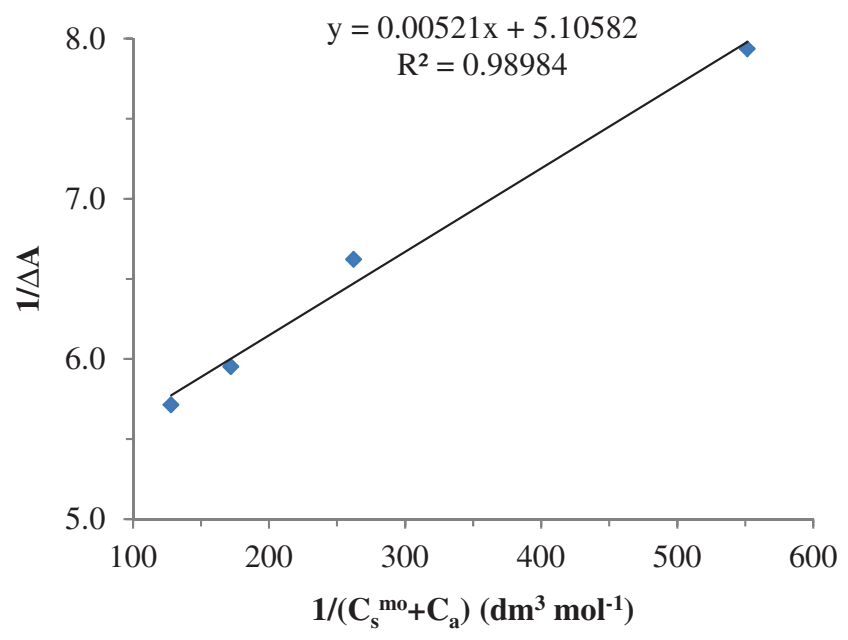

Figure 7. Calculation of $\mathrm{K}_{\mathrm{x}}$ using Kawamura model.

is calculated by using Kawamura equation (figure 7) which is given below. ${ }^{17}$

$$
\frac{1}{\Delta A}=\frac{1}{K_{c} \Delta A_{\infty}\left(C_{a}+C_{s}^{m o}\right)}+\frac{1}{\Delta A_{\infty}}
$$

Here, $\mathrm{C}_{\mathrm{a}}$ is concentration of drug $\left(\right.$ mole $\left.\mathrm{dm}^{-3}\right), \mathrm{C}_{\mathrm{s}}^{\mathrm{mo}}=$ $\mathrm{C}_{\mathrm{s}}-\mathrm{CMC}_{\mathrm{o}}$ in which $\mathrm{C}_{\mathrm{s}}$ is concentration of surfactant $\left(\right.$ mole $\left.\mathrm{dm}^{-3}\right)$ and $\mathrm{CMC}_{\mathrm{o}}$ is $\mathrm{CMC}$ of surfactant, $\Delta \mathrm{A}$ is differential absorbance, $\Delta \mathrm{A}_{\text {inf }}$ is differential absorbance approaches infinity and $\mathrm{K}_{\mathrm{c}}$ is partition constant in $\mathrm{dm}^{3}$ mole $^{-1}$ from which dimensionless partition coefficient $\left(\mathrm{K}_{\mathrm{x}}\right)$ is calculated as $\mathrm{K}_{\mathrm{x}}=\mathrm{K}_{\mathrm{c}} \mathrm{n}_{\mathrm{w}}$, where $\mathrm{n}_{\mathrm{w}}$ is number of moles of water in one $\mathrm{dm}^{3}$ of water and its value at $298 \mathrm{~K}$ is 55.4 . For LF/SDS system, $K_{x}$ has higher value representing that the concentration of drug in micelles is higher than that in surrounding aqueous phase. The value of $\mathrm{K}_{\mathrm{x}}$ is given in table 5 .

3.2d Free Energy of Partition: Free energy of partition $\left(\Delta \mathrm{G}_{\mathrm{p}}\right)$ is calculated by using following relation. ${ }^{17}$

$$
\Delta \mathrm{G}_{\mathrm{p}}=-\mathrm{RT} \ln \mathrm{K}_{\mathrm{x}}
$$

This parameter expresses the spontaneity of solubilization, a negative value means transfer of drug molecules from bulk of solution to micelles is spontaneous. As

Table 4. Concentration of surfactant, $\mathrm{C}_{\mathrm{s}}$, differential absorbance, $\Delta \mathrm{A}$, reciprocal of differential adsorption, $1 / \Delta \mathrm{A}$, for $\mathrm{LF}$ in SDS micellar media at $298 \mathrm{~K}$.

\begin{tabular}{lccccc}
\hline $\begin{array}{l}\mathrm{C}_{\mathrm{s}} \times 10^{3} \\
\left(\mathrm{~mol} \mathrm{dm}^{-3}\right)\end{array}$ & $\Delta \mathrm{A}$ & $1 / \Delta \mathrm{A}$ & $\begin{array}{c}\mathrm{C}_{\mathrm{s}}^{\mathrm{mo}} \times 10^{3} \\
\left(\mathrm{~mol} \mathrm{dm}^{-3}\right)\end{array}$ & $\begin{array}{c}\left(\mathrm{C}_{\mathrm{s}}^{\mathrm{mo}}+\mathrm{C}_{\mathrm{a}}\right) \times 10^{4} \\
\left(\mathrm{~mol} \mathrm{dm}^{-3}\right)\end{array}$ & $\begin{array}{c}1 /\left(\mathrm{C}_{\mathrm{s}} \mathrm{mo}+\mathrm{C}_{\mathrm{a}}\right) \times 10^{-3} \\
\left(\mathrm{dm}^{3} \mathrm{~mol}^{-1}\right)\end{array}$ \\
\hline 10 & 0.0301 & 33.22 & 1.80 & 18.13 & 0.551 \\
12 & 0.0340 & 29.41 & 3.80 & 38.13 & 0.262 \\
14 & 0.0374 & 26.74 & 5.80 & 58.13 & 0.172 \\
16 & 0.0407 & 24.57 & 7.80 & 78.13 & 0.127 \\
\hline
\end{tabular}


Table 5. Partition coefficient, $K_{x}$, free energy of partition, $\Delta G_{p}$, binding constant, $\mathrm{K}_{\mathrm{b}}$, and free energy of binding, $\Delta \mathrm{G}_{\mathrm{b}}$, for LF/SDS system at $298 \mathrm{~K}$.

\begin{tabular}{cccc}
\hline $\mathrm{K}_{\mathrm{x}} \times 10^{-4}$ & $\Delta \mathrm{G}_{\mathrm{p}}\left(\mathrm{kJ} \mathrm{mol}^{-1}\right)$ & $\mathrm{K}_{\mathrm{b}}$ & $\Delta \mathrm{G}_{\mathrm{b}}\left(\mathrm{kJ} \mathrm{mol}^{-1}\right)$ \\
\hline $5.4 \pm 0.01$ & $-26.99 \pm 0.02$ & $234.20 \pm 0.03$ & $-13.52 \pm 0.01$ \\
\hline
\end{tabular}

given in table $5, \Delta \mathrm{G}_{\mathrm{p}}$ is negative for the LF/SDS system showing spontaneous nature of partition process.

3.2e Drug/Surfactant Binding Constant: Binding constant can be calculated by following relation. ${ }^{18}$

$$
\frac{C_{s} C_{a}}{\Delta A}=\frac{C_{s}}{\Delta \varepsilon l}+\frac{1}{K_{b} \Delta \varepsilon l}
$$

Here, $\Delta \varepsilon$ is difference of absorption coefficient, 1 is path length, $\mathrm{K}_{\mathrm{b}}$ is binding constant (table 5).

3.2f Free Energy of Binding: Free energy of binding is calculated by following relation. ${ }^{18}$

$$
\Delta \mathrm{G}_{\mathrm{b}}=-\mathrm{RT} \ln \mathrm{K}_{\mathrm{b}}
$$

Negative value of $\Delta \mathrm{G}_{\mathrm{b}}$ for $\mathrm{LF} / \mathrm{SDS}$ shows spontaneous nature of binding process.

\section{2g Conductometric Study of LF/SDS Interaction:} Conductometric measurements for solutions of SDS of different concentrations containing $1.3175 \times 10^{-5}$ mol dm ${ }^{-3} \mathrm{LF}$ were taken at four different temperatures in the range $288-318 \mathrm{~K}$. The variation of conductance with concentration and temperature is shown in figure 8. Figure 8 shows that the conductance first increases rapidly with increase in concentration less than CMC of SDS and then slowly after CMC. Thus, two straight lines are obtained with different slopes when conductance is plotted versus concentration. The slope of the straight line is high in pre-micellar region and low in post-micellar region. The rapid increase in conductance before CMC is due to the reason that all the added molecules of SDS contribute towards conductance. Post-CMC, the newly added molecules go into micelles which are less mobile and also due to a decrease in concentration of free ions which cause a slow increase in conductance with concentration. ${ }^{19} \mathrm{~A}$ similar variation in conductance versus concentration is obtained for SDS in the absence of LF but the slopes of straight lines before and after CMC are different compared to those obtained for LF/SDS system which gives a different value of CMC. ${ }^{19}$

It is also found that the CMC of SDS in the presence of LF is different from that determined by absorbance measurements because the value of CMC determined depends on the type of physical property used. Moreover, absorbance measurements give approximate value of CMC while conductance measurements give more accurate value. ${ }^{18}$

It is apparent from table 6 that the CMC of SDS decreases in the presence of LF which indicates interaction of drug with micellization of SDS due to incorporation of drug molecules between the ionic head groups.

Free energy of micellization for LF/SDS system is more negative as compared to that in the absence of drug which shows that the process of micellization is more spontaneous in the presence of drug and occurs more readily. ${ }^{3}$

Enthalpy of micellization is less negative as compared to that in the absence of drug showing that the process of micellization is less exothermic in the presence of drug. ${ }^{3}$ Entropy of micellization has higher value in the presence of drug showing that greater increase in entropy occurs as a result of solubilization of drug into the micelles of SDS. ${ }^{3}$ Similar results have been reported by Bhardwaj et al., for the interaction of LF with SDS in which they used high concentration of drug, so a large decrease in CMC of surfactant was observed. ${ }^{7}$ Moreover, the free energy of micellization of SDS was found to be more negative and entropy of micellization more positive in the presence of $\mathrm{LF}^{7}$ as found in our study.

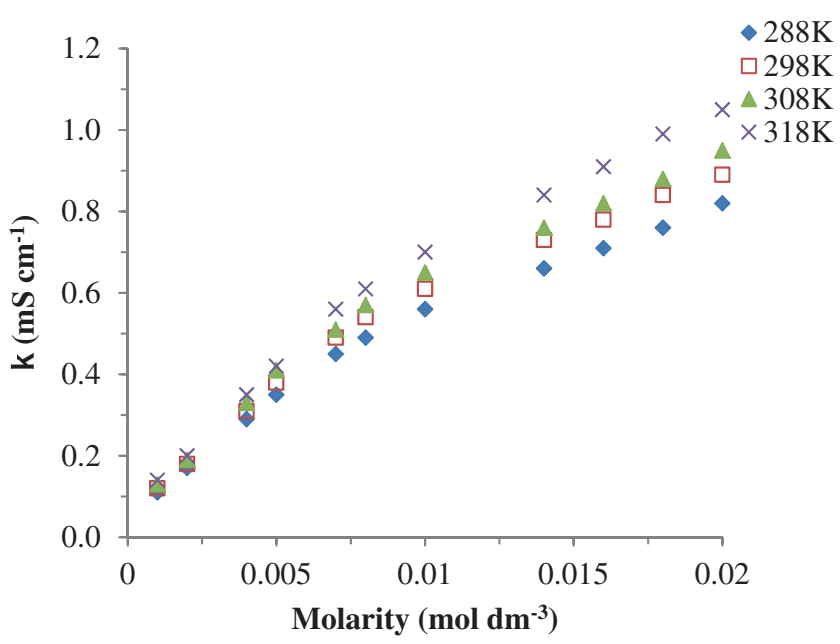

Figure 8. Electrical conductivity versus molarity plot for LF/SDS system at different temperatures. 
Table 6. Different parameters for the solubilization of LF into micelles of SDS.

\begin{tabular}{|c|c|c|c|c|c|c|c|}
\hline $\begin{array}{l}\mathrm{T} \\
(\mathrm{K})\end{array}$ & $\begin{array}{l}\mathrm{CMC} \times 10^{3} \\
\left(\mathrm{~mol} \mathrm{dm}^{-3}\right)\end{array}$ & $\begin{array}{c}\text { CMC } \\
\left(\mathrm{X} \times 10^{4}\right)\end{array}$ & $\underset{\left(\mathrm{kJ} \mathrm{mol}^{-1}\right)}{\Delta \mathrm{G}_{\mathrm{o}}^{\circ}}$ & $\begin{array}{c}\Delta \mathrm{H}_{\mathrm{m}}^{\circ} \\
\left(\mathrm{kJ} \mathrm{mol}^{-1}\right)\end{array}$ & $\begin{array}{c}\Delta \mathrm{S}_{\mathrm{m}}^{\circ} \\
\left(\mathrm{JK}^{-1} \mathrm{~mol}^{-1}\right)\end{array}$ & $\alpha$ & $\beta$ \\
\hline & & & & & & & 0.467 \\
\hline 298 & & & & $-9.68 \pm 0.40$ & & $0.536 \pm 0.009$ & $0.464 \pm 0.009$ \\
\hline & & & & $-10.33 \pm 0.42$ & & $0.516 \pm 0.002$ & $0.484 \pm 0.002$ \\
\hline 318.0 & $8.10 \pm 0.04$ & $1.47 \pm 0.07$ & $-34.80 \pm 0.03$ & $-10.68 \pm 0.46$ & $74.91 \pm 1.44$ & $0.492 \pm 0.001$ & $0.508 \pm 0.001$ \\
\hline
\end{tabular}

In table $6, \beta$ is degree of ionization of SDS in the presence of LF and is equal to $S_{2} / S_{1}$ in which $S_{1}$ and $S_{2}$ are the slopes of straight lines before and after CMC, respectively, when conductance is plotted versus concentration, while $\alpha$ is degree of counter ion binding and is equal to $1-\beta$.

\section{Conclusions}

CMC of LF was found to decrease with increasing temperature in ethanolic solution and increase in aqueous solution indicating dominance of lipophobic desolvation over lipophilic desolvation in ethanol and reverse in the case of aqueous solution. LF showed strong interaction with SDS in aqueous solution and the study showed the spontaneous nature of solubilization of drug into the micelles of SDS.

\section{References}

1. Shaikh M, Shafiq M and Farooqui M 2011 J. Adv. Sci. Res. 221

2. Usman M 2011 In The solution properties of amphiphilic drugs and their interaction with surfactants and human serum albumin $(\mathrm{Ph}$. D. Thesis Quid-e-Azam University, Islamabad, Pakistan) p. 6

3. Cheema M A, Taboada P, Barbosa S, Castro E, Siddiq M and Mosquera V 2008 J. Chem. Eng. Data 53368
4. Akbas H and Taner T 2009 Spectrochim. Acta, Part A 73 150

5. Khan A M and Shah S S 2008 J. Chem. Soc. Pak. 30186

6. Taboada P, Ruso M, Garcia M and Mosquera V 2001 Colloids Surf. A 179125

7. Bhardwaj V, Bhardwaj T, Sharma K, Gupta A, Chauhan S, Cameotra S S, Sharma S, Gupta R and Sharma P 2014 RSC Adv. 424935

8. Lafredo S C, Foleno B D and Fu K P 1993 Chemother. 3936

9. Usman M, Rashid M A, Mansha A and Siddiq M 2013 Thermochim. Acta $\mathbf{5 7 3} 18$

10. Akhtar F, Hoque M A and Khan M A 2008 J. Chem. Thermodyn. 401082

11. Usman M and Siddiq M 2013 J. Chem. Thermodyn. 58 359

12. Taboada P, Attwood D, Ruso M J, Garcia M, Sarmiento F and Mosquera V 2000 Langmuir 163175

13. Cheema M A, Taboada P, Barbosa S, Siddiq M and Mosquera V 2006 Mol. Phys. 1043203

14. Sarkar M and Poddar S 2000 J. Colloid Interface Sci. 221181

15. Naseem B, Sabri A, Hasan A and Shah S S 2004 Colloids Surf., B 357

16. Mishra A, Behera P K, Behera R K, Mishra B K and Behera G B 1998 J. Photochem. Photobiol. A 11679

17. Kawamura H, Manabe M, Miyamoto Y, Fujita $Y$ and Tokunaga S 1989 J. Phys. Chem. 93553

18. Shah S S, Laghari G M and Naeem K 1999 http:// serials.unibo.it/cgi-ser/start/it/spogli/df-s.tcl?prog_art=6 302921\&language $=I T A L I A N O \&$ view $=$ articoli. Thin Solid Films 346145

19. Santosh S and Nutan R 2011 Res. J. Chem. Sci. 122 